\title{
In Situ Nanoscale Investigation of Step Retreat on Fluoranthene Crystal Surfaces
}

\author{
Claudia-Corina Giese, ${ }^{\dagger, \ddagger}$ Helen E. King, ${ }^{*,+}$, Martijn P.A. van den Ende, ${ }^{\ddagger}$, Oliver Plümper, $^{\ddagger}$ \\ Inge Loes ten Kate, ${ }^{\ddagger}$ and Alexander G.G.M. Tielens ${ }^{\dagger}$ \\ ${ }^{\dagger}$ Leiden Observatory, Faculty of Science, Leiden University, 2300 RA Leiden, The Netherlands \\ ${ }^{\ddagger}$ Department of Earth Sciences, Faculty of Geosciences, Utrecht University, 3584 CB Utrecht, The Netherlands \\ ${ }^{\S}$ Géoazur, Université Côte d'Azur, 06560 Valbonne, France
}

Supporting Information

\begin{abstract}
Fluoranthene, a polycyclic aromatic hydrocarbon, has been detected on Earth as well as in asteroids and meteorites and may have played a role in the formation of life. Increasing the ionic strength of aqueous solutions has been observed to lower the fluoranthene solubility, but it is unclear how solution composition controls the release rate of fluoranthene to an aqueous solution. To elucidate this, we performed in situ atomic force microscopy experiments in which we characterized the sublimation and dissolution behavior of fluoranthene crystal surfaces. From this, we quantify the step retreat rate upon exposure to air, deionized water, and a $0.4 \mathrm{M} \mathrm{NaCl}$ or $0.1 \mathrm{M} \mathrm{MgSO}_{4}$ solution. Surface roughness is the main factor that determines the

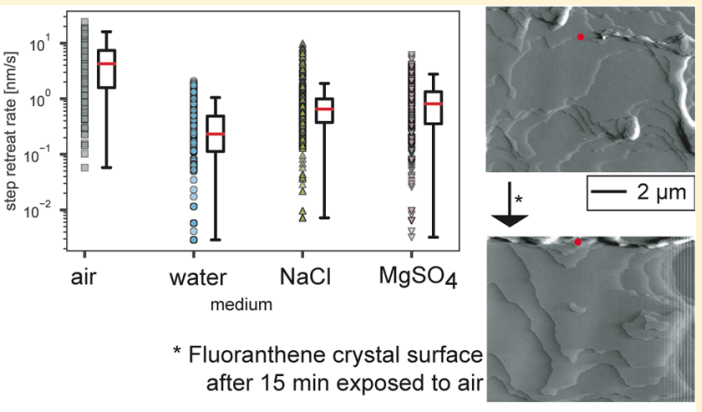
dissolution or sublimation rate. The results imply that during fluoranthene remediation or breakdown in meteorites and asteroids, ionic strength will be more important than chemical composition for controlling fluoranthene release into solution.
\end{abstract}

KEYWORDS: polycyclic aromatic hydrocarbons, atomic force microscopy, sublimation, dissolution, aqueous solutions

\section{INTRODUCTION}

Polycyclic aromatic hydrocarbons (PAHs) are ubiquitous on Earth as they form during the low temperature combustion of carbon-rich material. ${ }^{1,2}$ They are anthropogenically associated with coal and fossil fuel burning and produced endogenously through volcanism and forest fires. ${ }^{3-5}$ Extensive studies examining PAH interactions with fish have shown that PAHs are highly toxic to aquatic life. ${ }^{6,7}$ In addition, the majority of PAHs are considered carcinogenic for humans. ${ }^{8}$ Therefore, PAHs are considered to be pollutants. ${ }^{9,10}$ This means that understanding $\mathrm{PAH}$ distribution, mobility, and reactivity, which can remove $\mathrm{PAH}$ contaminants from a system, is of key environmental importance. Current removal and degradation processes for PAHs include sorption ${ }^{11}$ and chemical processes, e.g. ozonation, and UV radiation, ${ }^{12}$ and biodegradation via bacteria, fungi, or algae. ${ }^{13} \mathrm{PAHs}$ are also highly abundant in extraterrestrial environments. ${ }^{14-19}$ For example, they have been detected in carbonaceous chondrites, where they are incorporated during growth of the meteorite body and reach a concentrations of $15-28 \mathrm{ppm}$ per gram of meteorite. ${ }^{14}$ PAHs are of considerable interest in the context of asteroids, owing to their potential to serve as precursors for the formation of other organic molecules through aqueous alteration. $^{20}$ Therefore, for both the remediation of PAH contaminated environments on Earth and $\mathrm{PAH}$ reactivity in asteroids, liberation of the PAH molecules into the aqueous phase is critical.

Owing to the aromaticity of its $\mathrm{C}$ rings, PAHs are nonpolar and thus exhibit a low solubility in polar solvents such as water. $^{21}$ This occurs because, although the arrangement of water molecules around a nonpolar solute produces an exothermic enthalpic contribution, the increase in solvent molecule ordering generates a large entropic penalty. ${ }^{22}$ Therefore, there is a large thermodynamic driving force to remove the nonpolar solutes from solution, ${ }^{23}$ leaving them preferentially attached to mineral grains or other organic matter present. ${ }^{24}$ Previous studies have focused on measuring the solubility of $\mathrm{PAH}$ compounds under various aqueous conditions such as at different temperatures, ${ }^{21,25-27}$ pressurized water, ${ }^{28,29}$ and water with different degrees of salinity. ${ }^{27}$ However, PAH mobility and reactivity depend on solubility, an equilibrium thermodynamic parameter, as well as on the rate at which they are released from the solid phase, a kinetic parameter. At present, there is limited information about the rate of $\mathrm{PAH}$ dissolution and its dependence on the aqueous

Received: August 26, 2018

Revised: October 25, 2018

Accepted: November 2, 2018

Published: November 2, 2018 
Line intercept method

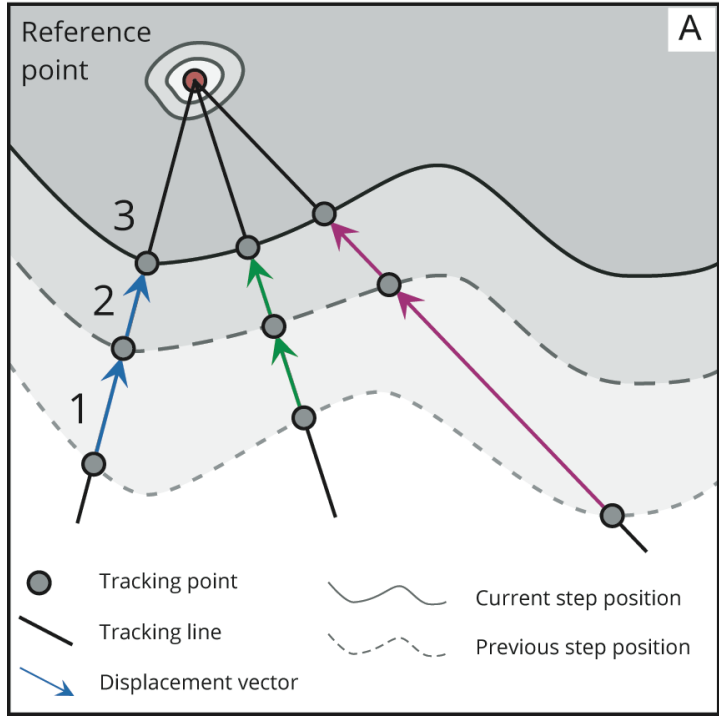

Point tracking method

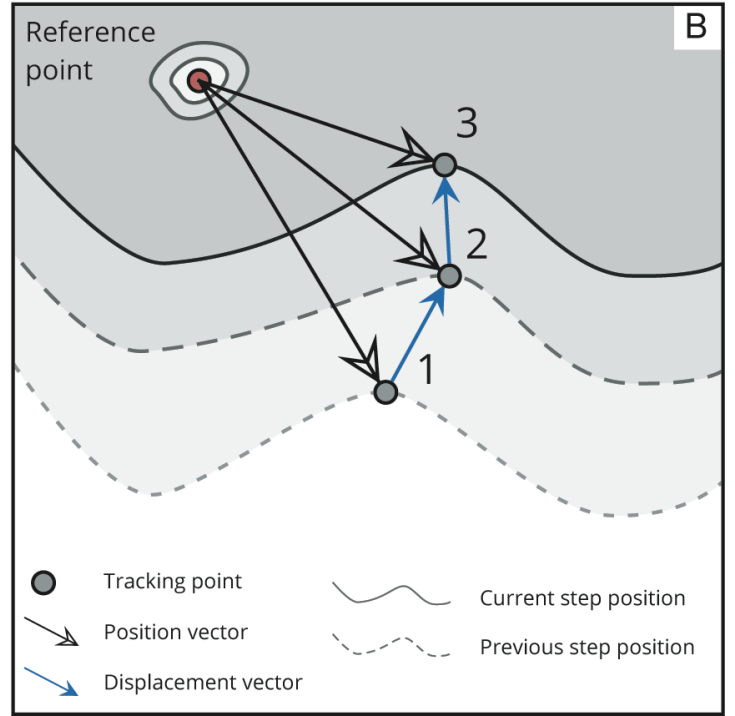

Figure 1. Line intercept (A) and the point tracking (B) method are illustrated in the schematic diagrams, as described in the method section. The position of a single distinctive feature (tracking point) on a given step is tracked across consecutive scans relative to an assumed stationary reference point. The step retreat rate is obtained from time differentiation of the position of the tracking point (numbers $1-3$ ) between consecutive scans. The tracking points measured are moving in the same direction (though this direction is not specified).

environment due to the low solubilities of PAHs in water and thus low concentration of molecules released into solution.

Recent mineralogical studies have used changes in crystal dissolution rate in the presence of different electrolytes studied in situ at the nanoscale to extrapolate changing hydration properties of solvated ions. ${ }^{30}$ High spatial resolution studies of PAHs are very limited. ${ }^{31}$ However, other organic crystals have been observed growing ${ }^{32}$ and dissolving ${ }^{33}$ in situ using atomic force microscopy (AFM) from the field of biology. ${ }^{34}$ On that basis, we examined how the solution composition controls the dissolution rate of the PAH fluoranthene. Fluoranthene has been chosen as a representative PAH in this study as it is stable as a solid at room temperature and pressure, but its solubility and vapor pressure are sufficient to measurably alter its surface structure over the duration from minutes to hours. This means that we can monitor the removal of material from a single crystal surface using AFM analysis. To our knowledge, there have been no studies of fluoranthene crystal surfaces; therefore, we first examined fluoranthene subliming into air. As the ionic strength of a solution has been shown to play a role in $\mathrm{PAH}$ solubility, ${ }^{27}$ we further studied fluoranthene dissolution in deionized water and $0.4 \mathrm{M} \mathrm{NaCl}$ or $0.1 \mathrm{M} \mathrm{MgSO}_{4}$ solutions, where the last two solutions have the same ionic strength.

\section{EXPERIMENTAL METHODS}

Atomic Force Microscopy. We performed experiments in which we exposed fluoranthene crystals (98\% purity, SigmaAldrich) to laboratory air (humidity: 50-80\%) followed by either deionized water, $0.4 \mathrm{M}$ sodium chloride $(\mathrm{NaCl})$ or 0.1 $\mathrm{M}$ magnesium sulfate $\left(\mathrm{MgSO}_{4}\right)$ solutions for up to $40 \mathrm{~min}$. The $\mathrm{NaCl}$ and $\mathrm{MgSO}_{4}$ solutions were prepared with sodium chloride and magnesium sulfate heptahydrate powder both from Merck, with a purity $\geq 99.5 \%$. The two different salts were chosen based on their abundance on Earth, ${ }^{35,36}$ where the composition of natural waters is mainly controlled by hydrogeochemical processes, ${ }^{37}$ and predictions of their importance as constituents of fluids in asteroids. ${ }^{38}$ In addition, these salts are expected to have different solvation and water structuring properties. ${ }^{39-41}$ The fluoranthene crystals used for the experiments are monoclinic with a columnar habit exhibiting large flat faces observable using a standard $10 \times$ magnification optical lens. These faces were used in the AFM experiments. Equilibrium calculations ${ }^{42}$ indicate that these large faces are a $\{101\}$ plane.

The untreated fluoranthene crystals were mounted onto a tetrafluoroethylene (TFE) sample holder using fluid carbon glue under a desktop fume hood. AFM measurements can be affected by tilting of the sample surface. Therefore, to limit tilting of the surface, the crystals were gently pressed onto the PTFE sample holder with a mica plate until they were observed to be level with the holder. The sample holder was then placed onto the piezoelectric scanner of the AFM. Realtime monitoring of the fluoranthene crystal surface in air or under aqueous solutions was carried out with a Nanoscope III Multimode AFM (Digital instrument; Bruker). The AFM cantilever was placed inside a glass probe holder (Model: MTFML; Bruker) with two tube entries for influx and outflow, referred to as a flow-through fluid cell, on top of the mounted sample holder. Images produced in the experiment were obtained in contact mode. We used a triangular nitride cantilever with a sharp silicon tip (average resonant frequency of $65 \mathrm{kHz}$ and a spring constant of $0.35 \mathrm{~N} / \mathrm{m}$, Model SNL-10; Bruker), which was replaced after each experiment. The crystals were always positioned with their long axis perpendicular to the cantilever.

During the experiments with fluids, the flow-through fluid cell was filled using a microfluidics syringe pump and kept filled with the aqueous solution. The experiments themselves were conducted in the absence of fluid flow. All experiments were carried out at room temperature. Images $(10 \times 10 \mu \mathrm{m})$ were taken in each experiment, and all surfaces were monitored over at least 20 consecutive scans to be able to follow the surface processes. Image analysis was conducted using the NanoScope Analysis program (version 1.5, Bruker). 
Determination of the Step Retreat Rate in Solution and Air. Line Intercept Method. To determine the step retreat rate, we employed the commonly adopted line intercept method (Figure 1a) with the AFM data obtained as deflection images. In this method, the translation of a step along a predetermined interception line is monitored over time. The (average) rate of translation (step retreat) was then taken as a measure for the material removal rate from the surface. For each sample, up to six intercept lines were defined, originating from an assumed stationary point (e.g., a deep etch pit nucleation point) and traversing the sample along arbitrary directions. The intersection points between these lines and steps were recorded for consecutively scanned images as a distance $d$ relative to the stationary point. The rate of step retreat $r$ was then estimated through a central differences scheme as

$$
r^{i}=\left|\frac{d^{i+1}-d^{i-1}}{t^{i+1}+t^{i-1}}\right|
$$

where $t$ denotes time, superscript $i$ denotes the current scan (i.e., current moment in time), $i-1$ the previous scan, and $i+1$ the subsequent scan. For the first and last scans, forward- and backward-Euler schemes were used, respectively.

In many previous studies employing the line intercept method, ${ }^{43}$ the steps are reported to be straight and continuous so that an intercept line can be chosen orthogonal to the strike of the step. In our samples, no single intercept line could be drawn that intersects all steps at $90^{\circ}$ angles for each given scan. The above approach thus yields an estimate of the true step retreat rate (see point tracking method below) that would, on average, be smaller by a factor $2 / \pi \approx 0.637$ due to misalignment between the intercept line and the direction of step retreat.

Point Tracking Method. In addition to the line intercept method described above, we estimated the rate of step retreat by tracking the position of individual points on a given step (see Figure $1 \mathrm{~b}$ ). The coordinates of a distinctive tracking point were recorded on each deflection image generated by consecutive AFM scans, resulting in a time-series of coordinate points. These coordinate points are inevitably affected by drift of the reference frame of the scanned area, which may be nonconstant and nonmonotonic in time. To correct for this, the coordinates of a reference point that was stationary on the sample surface (e.g., an etch pit) were recorded in addition to the step tracking points. The position of the tracking points $\left(x_{\mathrm{p}}\right)$ was then calculated relative to the position of the reference point $\left(x_{\mathrm{r}}\right)$, eliminating drift of the scanned area position. The step retreat velocity $v$ at time $t$ was estimated in a central differences scheme as

$$
v^{i}=\frac{\left(x_{p}-x_{r}\right)^{i+1}-\left(x_{p}-x_{r}\right)^{i-1}}{t^{i+1}-t^{i-1}}
$$

The rate of step retreat is then expressed as the magnitude of $v$, i.e. $r=\sqrt{v_{x}^{2}+v_{y}^{2}}$. The rates obtained by the point tracking method were compared with those obtained by the line intercept method and were expected to fall toward the high end of the range of intercept method measurements, as mentioned in the above section. Results obtained from the line intercept method lie within the scatter of the point tracking method. Therefore, the line intercept method, which yielded more data points, was used to determine the rates used in the averages over many surfaces. For an in-depth image by image analysis of steps on a surface exposed to air, the point tracking method was used. This allowed us to produce a detailed vector map of the step movement across the surface.

Sample Surface Roughness. Maps of the sample topography generated by the AFM scans were processed to obtain a quantitative measure of the sample surface roughness. Each pixel in an image was converted to a surface height value $h$ relative to an arbitrary point. The surface roughness $R_{\mathrm{q}}$ was then expressed as the standard deviation of $h$ around the mean $\bar{h}$, i.e. as the root mean squared roughness (for $n \gg 1$ ):

$$
R_{\mathrm{q}}=\sqrt{\frac{\sum_{i=1}^{n}\left(h_{i}-\bar{h}\right)^{2}}{n-1}}
$$

As the surface roughness is determined for each AFM scan individually, the time evolution of roughness can be directly correlated with the time evolution of step retreat rates.

\section{RESULTS}

Surface Features. Although the sample surfaces appear flat in the light microscope, they show a range of topographies at the nanometer scale (Figure 2). The crystal surfaces had flat areas (terraces) between steps in all studied media. The step edges were undulating both at the $100 \mathrm{~nm}$ and $\mu \mathrm{m}$ scales (seen in Figures $2 \mathrm{a}$ and $\mathrm{b}$ ). Undulations at the $\mu \mathrm{m}$ scale can be related to islands of higher topography, which appear to pin the steps at these points. Retention of steps at the island sites is
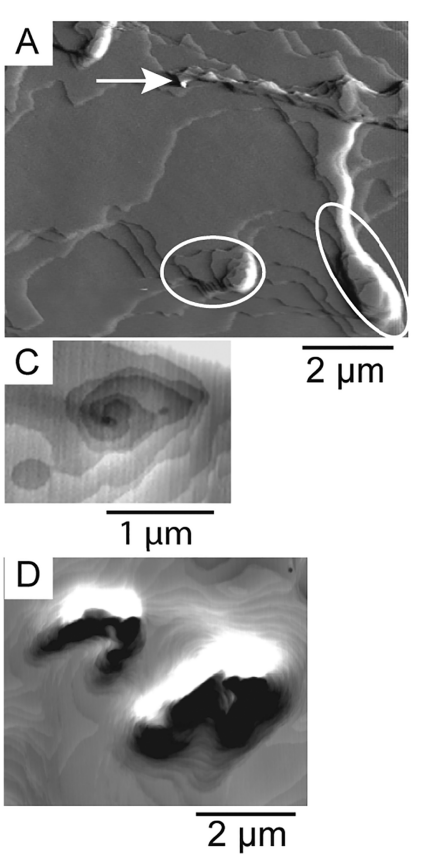

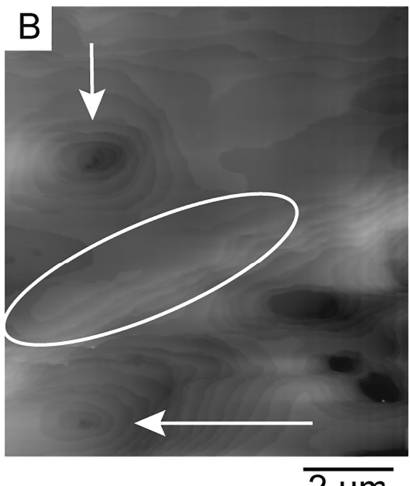

$\overline{2 \mu \mathrm{m}}$

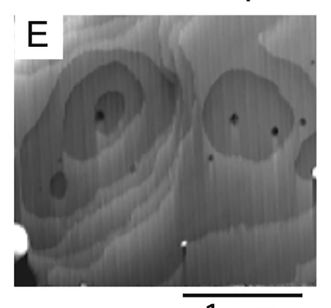

$1 \mu \mathrm{m}$
Figure 2. Examples of features observed on the fluoranthene crystals. (A) Fluoranthene surface after exposure to air. Free-moving and pinned steps (in between islands indicated by the white ovals) are depicted; an isolated etch pit (white arrow) is observed in the center at the top of the image. (B) Fluoranthene surface after exposure to 0.1 $\mathrm{M} \mathrm{MgSO}_{4}$. Several types of etch pits are present; isolated area (surrounded by the white oval) formed by interaction of steps from different etch pits. (C) A dissolution spiral formed during fluoranthene surface exposed to deionized water. (D) Tick-shaped deep etch pit cluster. (E) Shallow etch pits that spread in discrete layers. 


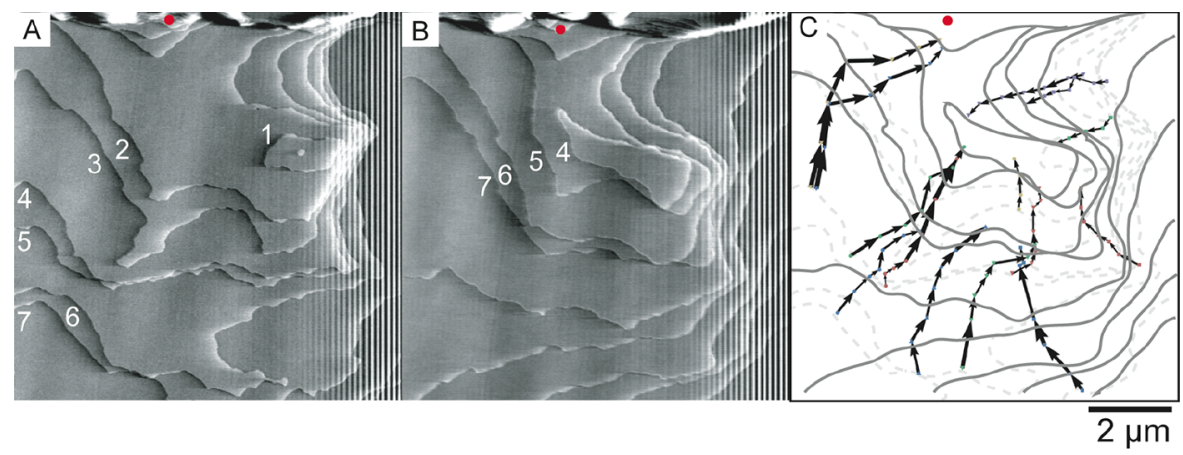

Figure 3. Fluoranthene crystal surface exposed to air. The red dot in A and B is an isolated etch pit that is used as the stationary reference point to account for instrument drift. The transition from the surface A to B took $7 \mathrm{~min}$. The steps are consecutively numbered, and the same numbering is used in A and B. (A) Deflection image of the initial surface at the start of the measurement sequence. Numerous bunched steps define an island (number 1). (B) Deflection image of surface at the end of the imaging sequence showing the final location of the steps and the eradication of three initially identified steps, but also appearance of new steps. (C) Vector image tracking the steps as they move across the surface. Each spot is the new position in the subsequent scan image. The arrows are scaled to represent step speed and direction between each image, where a larger arrow indicates a faster speed of step retreat. The vectors show that step retreat is generally faster further away from the islands. For reference, dashed and solid gray lines indicate traces of the steps identified in panels A and B, respectively.
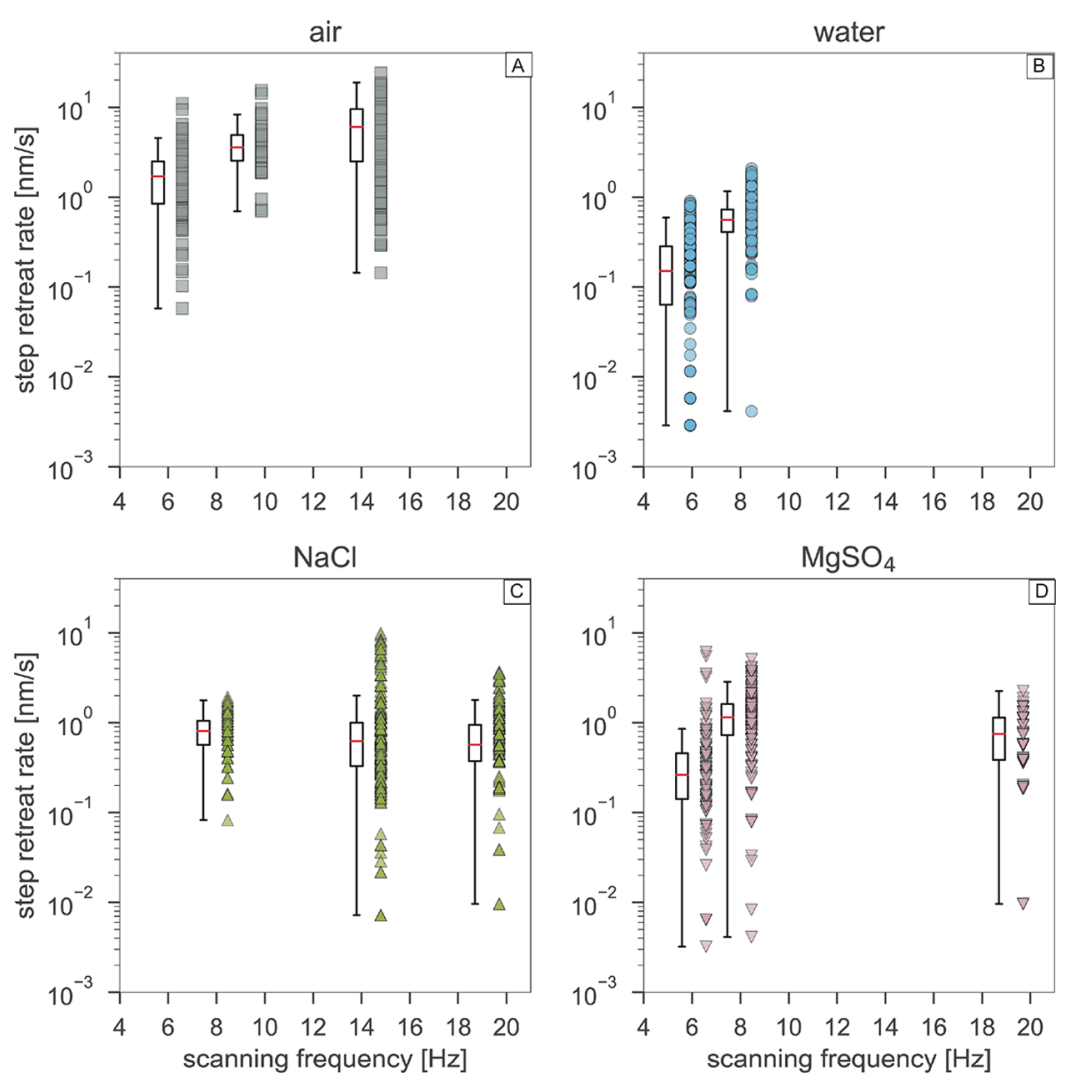

Figure 4. Step retreat rates against tip scanning frequency for (A) air, (B) deionized water, (C) $0.4 \mathrm{M} \mathrm{NaCl}$ solution and (D) $0.1 \mathrm{M}$ $\mathrm{MgSO}_{4}$ solution. The data points are obtained from the linear intercept method. No systematic effect of the tip interaction with the surface on the step retreat rates is observed. The whiskers indicate the 1.5 interquartile ranges.

also suggested by the observation that the sides of the islands consist of numerous steps in close proximity to one another (Figure 2a). When the surface is imaged progressively over the duration of several minutes, the steps that are identified in the initial image are observed to retreat across the surface. Top surface layers and island structures are eradicated over time by step coalescence.

Shallow etch pits (Figures $2 \mathrm{~b}$ and e) were observed that had coalesced to form the undulated step edge texture at the 100 $\mathrm{nm}$ scale. These etch pits were more abundant on surfaces exposed to aqueous solutions. In addition, the images show deeper etch pits that can be separated into two different types: (1) stationary pits that remained at least $18 \mathrm{~nm}$ below the highest step that defines their rim, and (2) broader, deep etch pits found individually or in clusters (Figure 2d), forming a line or tick-mark-like structure. Steep sided, deep etch pit clusters did not widen during the experiments. However, small steps could break free at the top of the etch pit cluster, and these small steps retreated across the surface. Deep, individual etch pits widened during the experiments, developing small terrace 


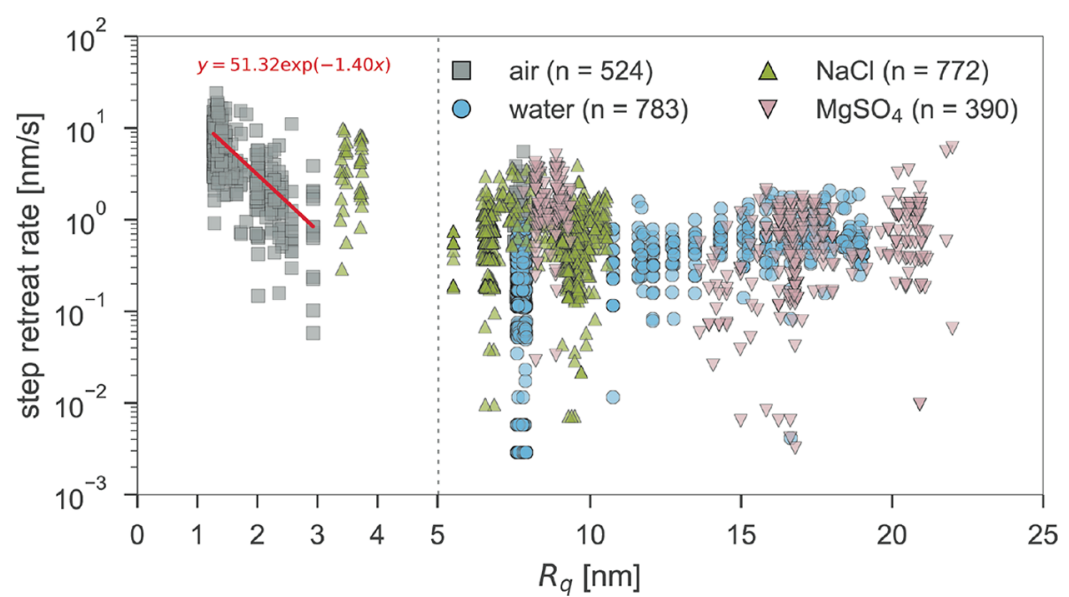

Figure 5. Step retreat rates against root-mean-square roughness. The data points are obtained by the linear intercept method. Data for which $R_{\mathrm{q}}<5$ $\mathrm{nm}$ show an exponential decline in step retreat rates with increasing $R_{\mathrm{q}}$, which saturates for $R_{\mathrm{q}}>5 \mathrm{~nm}$ for all solutions. Note the use of a discontinuous $x$-axis.

areas between the steps that comprised the etch pit walls. Both shallow and deep etch pits formed a circular indentation when isolated from other etch pits (Figures $2 \mathrm{~d}$ and e). This circular shape changes to oval or a more irregular shape when the steps defining the etch pit edge approach surrounding surface features, such as other etch pits and islands. The change in shape was not found to be dependent on the specific direction of step retreat across the surface. Steps that defined the edges of the shallow etch pits also migrated across the surface with time, exposing new material to the medium. New shallow etch pits nucleated in the same location on the newly exposed surface. Deep etch pits from which steps were liberated appeared to become shallower with time. In one experiment in deionized water, two spiral etch pits were also observed (Figure 2c), which generated new steps on the surface. Newly generated steps retreated across the surface away from the center of the etch pit that generated them.

Surface Effects on Step Retreat. Individual steps were observed to retreat at different rates dependent on the spacing between their neighboring steps and distance to other topographic surface features (Figure 3) but independent of their retreat direction. Steps that retreated with a spacing closer than $\sim 100 \mathrm{~nm}$ apart showed identical retreat rates. In contrast, steps that were spaced further apart exhibited distinctly different retreat rates. Steps that migrated at similar rates were observed to eventually diverge during the experiment. In the vicinity of an island, the step retreat decelerated but accelerated again once the island structure was passed. This behavior may have been caused by direct interaction of the AFM tip with the sample surface. However, experiments conducted at different tip scanning rates showed no correlation between scan frequency and step retreat rates (Figure 4), suggesting that the AFM tip exerted minimal influence on the material removal rate from the surface. Similarly, no difference in surface features was observed outside of the repeatedly scanned area.

Effect of Medium Composition on Retreat Rates. Surface topographic features clearly had a significant impact on individual step retreat rates. Despite showing similar surface features, the topography of each surface examined was distinct and evolved with time. Therefore, we compared the step retreat rates between various solvents as a function of the surface roughness, expressed as roughness value $R_{\mathrm{q}}$. Figure 5 shows that at low roughness values $\left(R_{\mathrm{q}}<5 \mathrm{~nm}\right)$, the step retreat rate decreased with increasing $R_{\mathrm{q}}$. In the example of the samples exposed to air a decrease with an exponential descent is observable. However, samples with $R_{\mathrm{q}}$ above $5 \mathrm{~nm}$ show no effect of surface roughness. Higher surface $R_{\mathrm{q}}$ is consistent with observed areas with step bunching, which is associated with islands or areas isolated by the edges of etch pits. In these areas, steps migrate more slowly than on large, flat terrace areas. The experiments in air show a dependence on roughness; thus, determination of a representative average rate is hindered by the high variability of step retreat rates. At $R_{\mathrm{q}}$ above $5 \mathrm{~nm}$, the calculated retreat velocities for the different aqueous media are independent of surface roughness within the data scatter.

Plotting the distributions of step retreat rates of all media combined (Figure 6) demonstrates that rates within a single experiment can vary by an order of magnitude on the fluoranthene surface. The box and whisker plot (Figure 6) of the retreat rates also shows that the data is slightly more closely clustered for the $\mathrm{NaCl}$ experiments in comparison to deionized water and $\mathrm{MgSO}_{4}$ solution experiments. The median of the step retreat rates demonstrate that dissolution is consistently

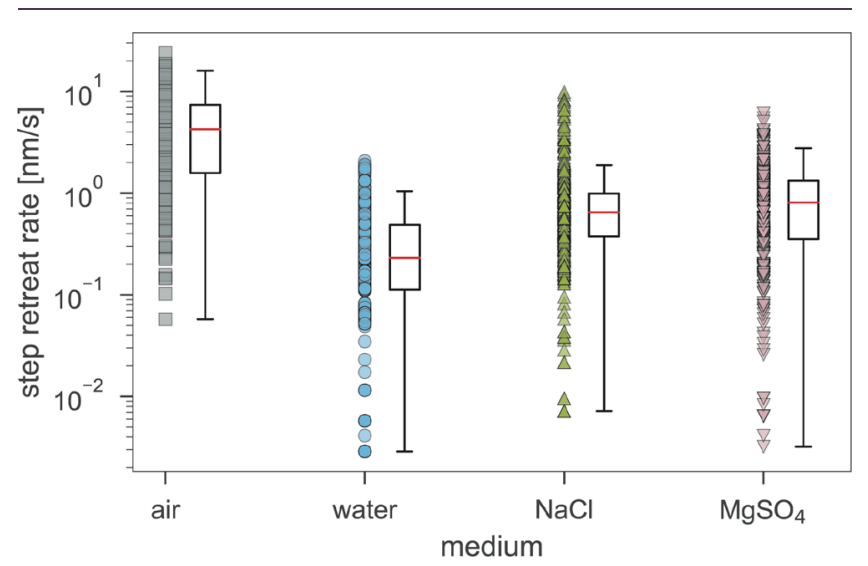

Figure 6. Box and whisker plot of step retreat rates for the different media. The whiskers indicate the 1.5 interquartile range. The data points are obtained from the linear intercept method. Step retreat in air was the fastest in our experiments, followed by $\mathrm{MgSO}_{4} \approx \mathrm{NaCl}>$ deionized water. 

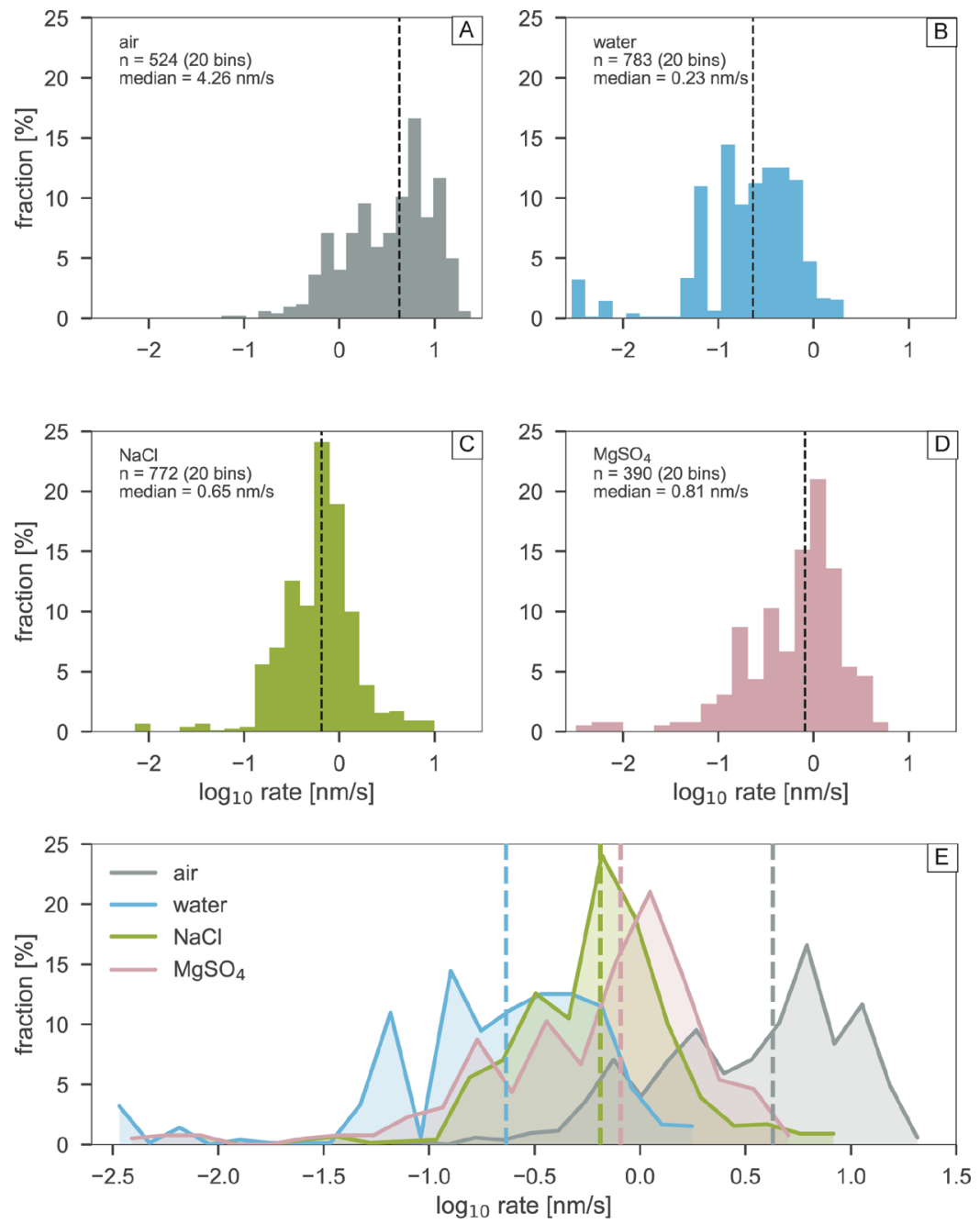

Figure 7. Histograms of the step retreat rates for air, deionized water, $0.4 \mathrm{M} \mathrm{NaCl}$, and $0.1 \mathrm{M} \mathrm{MgSO}_{4}$ solutions. The step retreat rates are not normally distributed and are skewed to faster rates. For easy comparison, the histograms in panels A-D are joined in panel E.

faster in the higher ionic strength solutions (Figure 6), i.e. the $0.4 \mathrm{M} \mathrm{NaCl}$ and $0.1 \mathrm{M} \mathrm{MgSO}_{4}$ show faster retreat rates than deionized water $(0.23 \mathrm{~nm} / \mathrm{s}$ on average $)$. In addition, dissolution in $\mathrm{MgSO}_{4}$ solution $(0.81 \mathrm{~nm} / \mathrm{s})$ appears faster than in the $\mathrm{NaCl}$ solution $(0.65 \mathrm{~nm} / \mathrm{s})$, although the difference between these rates falls within the scatter of the data. The data do not show a normal distribution (see Figure 7), similar to what has been observed previously with rate distributions that examine different reactive sites on a dissolving surface. ${ }^{44,45}$ Following these studies, we fitted several common distributions to the data using Python's SciPy library. ${ }^{46}$ However, none of these distributions adequately described the data distribution, as concluded from Kolmogorov-Smirnov tests (see Supporting Information for details). As the data was nonnormal in distribution, the boot strapping method was used to assess the statistical significance of the mean step retreats obtained from each of the different media. The statistical analysis indicates that the difference between the mean step retreat rates of the $0.4 \mathrm{M} \mathrm{NaCl}$ and $0.1 \mathrm{M} \mathrm{MgSO}_{4}$ solutions is only slightly statistically significant, where the $0.1 \mathrm{M} \mathrm{MgSO}_{4}$ solution is faster than the $0.4 \mathrm{M} \mathrm{NaCl}$ solution. However, even though the difference is statistically significant, it may lie within the experimental uncertainty (e.g., uncertainty due to sample preparation and the limited size of the scanned area). It can therefore not be conclusively stated that solution composition has an effect on the step retreat rates, other than through its ionic strength.

\section{DISCUSSION}

Topography Effect on Fluoranthene Release. Previous experiments conducted in an AFM have shown dissolution of organic crystals occurs via steps and etch pit formation, ${ }^{47,48}$ as is observed in our experiments. In the previous experiments, etch pit shapes were dictated by the crystallographic arrangement of the organic molecules that make up the macromolecular crystal. In these cases, the steps that delineate the etch pit edge occurred in directions of periodic bonding chains. ${ }^{47}$ Differences in step retreat rate related to specific crystallographic directions thus led to characteristic etch pit shapes. However, in our experiments, the direction of step retreat did not produce a measurable difference in the rates. This indicates that step retreat on the fluoranthene surfaces was not controlled by atomic interactions in specific crystallographic directions. This is consistent with the formation of circular etch pits when steps are able to freely move across the surface. For inorganic crystal systems, step retreat has also been linked to the population of reactive sites at the step edges called kinks. ${ }^{49-51}$ The rate of kink formation and their annihilation via coalescence can also play an important role 
in the rate of step retreat. ${ }^{51}$ However, rough or curved steps, such as those observed on the fluoranthene surface, are considered to have maximum kink density, indicating that retreat rate is more likely controlled by other processes such as surface diffusion of released molecules away from the step face. $^{49}$

Retreat rate dependence on surface diffusion is consistent with observations from our experiments, where interactions between moving steps and surface topography that results in step bunching have a large influence on the step retreat rates measured for fluoranthene (Figure 5). Step bunching on inorganic crystal surfaces has been attributed to different phenomena, including anisotropic detachment kinetics driven by diffusive transport, ${ }^{52-54}$ strain mediated step bunching, ${ }^{55,56}$ and impurity induced step bunching. ${ }^{57}$ Adsorption of impurities to steps in aqueous solution is known to change the shape of retreating step edges and overall morphology of etch pits in both inorganic ${ }^{58}$ and organic ${ }^{47}$ crystals. Yet, in our experiments, we see no significant difference in the step morphology between air and aqueous solution, indicating that adsorption of impurities to step edges is unlikely to cause the step bunching. Similarly, impurities already present in the crystal structure would be expected to be associated with etch pit nucleation during material removal from the surface. Therefore, impurities are not expected to cause step bunching. Strain induced bunching is typically linked to the application of thin films in the silicon literature. ${ }^{59}$ As we used crystal faces and there does not appear to be a directional bunching behavior, it also seems unlikely that bunching is caused by strain at the surface. Thus, the most likely cause of step bunching in our experiments is anisotropic diffusive transport, consistent with the expected controls of step retreat rate when kink site density is maximized at curved steps.

When steps are closely spaced, the solute concentration gradients between neighboring steps start to orient themselves normal to the sample surface as a consequence of the accumulation of released molecules (Figure 8). This is

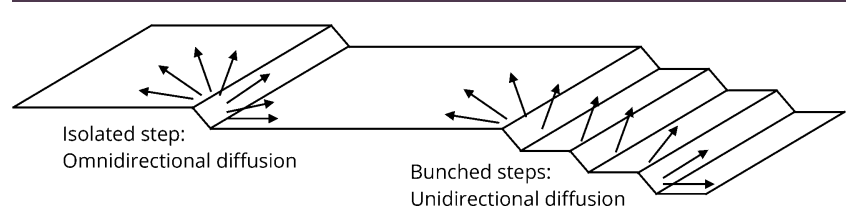

Figure 8. Schematic diagram illustrates a model for diffusioncontrolled step retreat. Isolated steps are unaffected by neighboring steps, and dissolved species can diffuse away from the reaction site in all directions. When steps are in close proximity to one another, diffusion may occur only normal to the crystal surface, inhibiting step retreat as solute concentration accumulates.

expected to inhibit diffusion in the tangential directions so that diffusion may occur only in the direction normal to the surface. As a result, the overall rate of diffusive transport decreases, leading to lower step retreat rates in the vicinity of steep topographic features where steps are closely spaced. For example, the interactions between the steps that comprise the etch pit walls in the deep, clustered etch pits (e.g., those in Figure 2d) results in these steps being unable to move. Therefore, although single steps at the surface can free themselves from the deep cluster etch pit walls, the etch pits themselves do not widen during the experiments. In contrast, the steps that define the walls of single deep etch pits can retreat and are observed to separate to form terrace areas.
When several of the single, deep etch pits are close together, retreat of the wall steps toward another etch pit isolates areas of the surface (Figure $2 b$ ). Interaction between the steps of the etch pit walls on either side of the isolated area results in this area becoming more resilient to material removal.

Islands (Figure 2a, Figure 3) constitute the most complex topography on the surface of a fluoranthene crystal. In our experiments, once the steps have approached an island, the steps decelerate and enclose it, which results in step coalescence and perpetuation of the quasi-circular geometry of the islands (see Figure $3 c$ and the video in the Supporting Information). Steps that have been separated from the island by coalescence (and have passed the island) accelerate in retreat rate and continue to translate over the surface. Deceleration of step retreat upon interactions with surface features has been observed previously during the sublimation of silicon. ${ }^{59}$ Steps close to the surface feature are slowed, while sections of the step away from the feature move at a higher rate. This produces a characteristic undulatory shape of the step, as is most clearly observed in our experiments with air at locations where the steps interact with two islands (Figure 2a). Islands are perpetuated on the fluoranthene surface through the slower step retreat caused by anisotropic diffusion in areas of step bunching, such as the sides of islands. Therefore, the presence of islands encourages the generation of nonstraight step morphologies, facilitating the retention of step retreat dependence on surface diffusion rather than kink density at step edges.

Influence of Solution Composition on Fluoranthene Dissolution. Step retreat during fluoranthene dissolution showed minimal crystallographic orientation control as the etch pits are circular and spread evenly, similar to what has been observed in other monoclinic materials. ${ }^{60}$ Therefore, our experiments illuminate the interactions of fluoranthene with the solution, with little crystallographic controls on the dissolution rate. Changes in the composition of the solution itself may thus explain the change in step retreat rate observed in the different fluids tested (Figure 6). Increasing the ionic strength of aqueous solutions is known to decrease the solubility of most PAHs, ${ }^{27}$ referred to as the salting out effect. ${ }^{61}$ For example, Jonker and Muijs $(2010)^{62}$ show that fluoranthene increases its partition coefficient between the solid and aqueous phases by $70 \%$ when the ionic strength of the aqueous solution increases. Therefore, we expect that the solubility of fluoranthene is lower in the $0.4 \mathrm{M}$ ionic strength solutions in comparison to the deionized water experiments.

When ions are added to an aqueous solution, a hydration shell of water molecules surrounds them, controlling the local structure of the water medium. Ions in solution have also been suggested to alter the long-range hydrogen bonding structure of the water medium to different extents. ${ }^{63}$ Thus, the inclusion of salts in solution has direct implications for the enthalpy and entropy of the system. The low solubility and salting out effect of organic molecules at high ionic strengths ${ }^{61}$ is closely associated with the entropic and enthalpic conditions of the system. Therefore, the presence of specific ions in solution has a direct influence on the ability of organic molecules to be solubilized. In particular, decreased solubility for neutrally charged organic molecules, such as PAHs, has been associated with an increase in polar interaction energies between water molecules as well as the energy for cavity formation within the bulk water structure, which is required to accommodate the organic molecules. ${ }^{64}$ For the ions tested in our experiments, 
$\mathrm{Na}^{+}$has minimal effect on the water structure, whereas $\mathrm{Mg}^{2+}$ is known to be a strong water structure-making ion. ${ }^{63}$ In contrast, $\mathrm{Cl}^{-}$is a strong water structure-breaking ion, with $\mathrm{SO}_{4}{ }^{2-}$ exhibiting weaker structure breaking to structure making characteristics. ${ }^{63}$ Therefore, we expect that the $\mathrm{NaCl}$ solution will be water structure breaking to weakly structure making, whereas the $\mathrm{MgSO}_{4}$ solution will be dominantly structure making. This is consistent with work on $\mathrm{MgSO}_{4}$, which shows that the cooperation of the two ions can significantly change the water structure outside of the first hydration shell. ${ }^{65}$ As our solutions had the same ionic strength, the strong hydration of $\mathrm{Mg}^{2+66}$ and $\mathrm{SO}_{4}{ }^{2-66,67}$ as well as the structure making characteristics of $\mathrm{MgSO}_{4}$ imply that a more dominant salting out effect will occur for fluoranthene in $\mathrm{MgSO}_{4}$ solutions in comparison to $\mathrm{NaCl}$ solutions.

In our experiments we observed homogeneously distributed shallow etch pits in all solutions, which are associated with a large shift from equilibrium. ${ }^{68}$ Given the salting out series for fluoranthene in the solutions we studied, the expected sequence of dissolution rates (if dissolution rates are correlated directly with solubility) is thus: deionized water $\gg \mathrm{NaCl}>$ $\mathrm{MgSO}_{4}$. However, the measured step retreat rates from our experiments do not fit with the expected solubility sequence. Instead, they follow the trend $\mathrm{MgSO}_{4} \geq \mathrm{NaCl}>$ deionized water. This implies that the favorability of water to form a cavity does not account for our observed step retreat rates.

In previous $A F M$ experiments with inorganic crystals, the solution ions also appear to affect the structure of water at the crystal surface. ${ }^{58,69}$ This has been linked to water exchange kinetics both between the ions in solution and ions at the crystal surface. In inorganic crystals, water structures itself above exposed ions at the crystal surface. ${ }^{70}$ However, the charge neutrality and nonpolarity of fluoranthene would be expected to limit the water structuring at the interface. Yet, step retreat rates were higher in the presence of salts in the solution. Absence of an observable change in the etch pit or step shapes in the different solution experiments indicates that there is no direct interaction between the salt ions and the fluoranthene surface. In addition, no evidence for increased rates of step retreat were observed at higher AFM scan rates in the aqueous solutions, indicating an importance of surface diffusion rather than diffusional barriers normal to the surface. There were differences in the distributions of the step rates measured in the different solutions (see Supporting Information); however, the direct cause of these differences is not clear from the experiments. We are not aware of any study that has described the diffusive properties of fluoranthene molecules in aqueous solutions in the presence of structure altering ions. We can therefore only hypothesize that high ionic strength solutions result in a larger diffusion coefficient of fluoranthene species at the crystal surface, which could counteract the diminished solubility by facilitating molecule transport through the salt solutions. This would give rise to the observed order of step retreat rates. However, further studies on the diffusivity of fluoranthene are necessary to further test this hypothesis.

Implications for Fluoranthene in Natural Systems. Natural fluoranthene exists on Earth as a gaseous or particulate phase, ${ }^{1}$ where it is most likely in the form of disordered macromolecules. ${ }^{71}$ Examples of PAHs in air and aqueous environments on Earth demonstrate that these macromolecules are preferentially partitioned onto solid particles, which it is crucial for their availability and transportability. ${ }^{24}$ Similarly, a study by Zenobi et al. ${ }^{72}$ on Allende indicates that
PAHs are not homogeneously distributed within carbonaceous chondrites but are instead associated with the organic polymer that comprises the main carbonaceous phase. In amorphous fluoranthene, the solid phase is joined together via van der Waals and $\pi-\pi$ intermolecular bonding. ${ }^{71,73}$ Similarly, the interactions between PAHs and organics such as active carbon are considered to be associated with $\pi-\pi$-, $\mathrm{H}-\mathrm{H}$ - and electron donor-acceptor-bonding mechanisms. ${ }^{74,75}$ For the interaction between PAHs and other organic matter, similar modes of intermolecular bonding are typically assumed, although the exact nature of the bonding will depend upon the chemical structure and characteristics of the molecules involved. ${ }^{76}$ As in the amorphous system, intermolecular bonding within the fluoranthene crystal also occurs via $\mathrm{H}-\mathrm{H}^{-77}$ and van der Waals $^{78}$ interactions. Therefore, the intermolecular interactions should be similar in our experiments and more amorphous material in natural systems.

Tremblay et al. ${ }^{79}$ showed that the adsorption of PAHs to humic acid and sediment particulates corresponds to changing solubilities, thus salting out. As our experiments in fluid show minimal crystallographic orientation control, we suggest that the rates produced reflect changes in the interaction with the surrounding solution, which will also be important for amorphous materials found in nature. As dissolution rates of amorphous solids are significantly faster than those of crystalline counterparts, ${ }^{80}$ our experiments are expected to show a lower rate than could arise in natural systems, where an amorphous phase is present.

PAH redistribution on Earth is proposed to occur via the transport of particulates onto which they are absorbed ${ }^{24,81}$ as their solubility is too low for them to be retained in solution at high concentrations. Fluoranthene's lower solubility but faster dissolution rates in saline solutions indicate that in these environments fluoranthene will quickly equilibrate with the fluid at a particle interface. Therefore, if fluid mixing rates are slow, fluoranthene will have a very low mobility in these environments. In contrast, this may be different for interfacelimited systems where equilibrium cannot be reached due to replenishment of the interfacial solution. Thus, fluid transport could play an important role in the liberation of PAHs from solid matter, resulting in faster $\mathrm{PAH}$ removal rates into the interfacial solution than would be predicted from solubility alone. In chemical degradation processes for PAH contamination remediation, including those targeting fluoranthene, the PAHs need to be dissolved into solution ${ }^{82}$ before they can react. As the $\mathrm{PAH}$ is removed from the system in these processes, equilibrium will not be reached if the rate of reaction is faster than the dissolution rate. Thus, if the rate of degradation is limited by the rate of $\mathrm{PAH}$ dissolution, our results imply that changing the ionic strength and composition of the reacting solution may assist degradation rates.

In carbonaceous chondrites aqueous alteration has been proposed to occur at temperatures ranging from 0 to $300{ }^{\circ} \mathrm{C} .{ }^{83}$ $\mathrm{PAH}$ mobility depends on the compound's solubility and dissolution rate under these conditions. Oparin et al. ${ }^{84}$ demonstrated that there is very little change of water structuring in solutions containing $\mathrm{NaCl}$ between 1 and 1000 bar. Therefore, assuming that the solubility remains associated with water structuring, we do not expect pressure to significantly change the solubility of PAHs within meteorites or asteroids. In contrast, the solubility of PAHs has been shown to increase with increasing temperature up to their melting point. ${ }^{27,85}$ Increasing temperature from 25 to $250{ }^{\circ} \mathrm{C}$ 
was shown to decrease the water structure dependence on $\mathrm{Na}^{+}$ and $\mathrm{Cl}^{-}$ions. ${ }^{84} \mathrm{Mg}^{2+}$ can retain its first hydration shell up to at least $125{ }^{\circ} \mathrm{C}$, but enhanced ability to form complexes with other ions in aqueous solution implies that the second or third hydration shells are disrupted at higher temperatures. ${ }^{86}$ The effects of ionic strength and solution composition on $\mathrm{PAH}$ dissolution will therefore become negligible at higher temperatures. Thus, PAH mobility in meteorites will depend on solution composition only at lower temperatures of aqueous alteration. A higher ionic strength at these temperatures will result in a lower concentration of PAHs in solution. The solution composition will play an important role in the rate of fluoranthene release into solution in this case, where the presence of high concentrations of $\mathrm{Mg}^{2+}$ is expected to enhance PAH retention in the solid phase if fluid transport is low.

\section{CONCLUSIONS}

Our experiments agree with previous studies of organic crystals $^{87}$ which demonstrate that AFM surface analysis is a powerful tool to probe the effect of ionic strength and solution composition on the release of nonpolar, charge neutral organic molecules from crystal surfaces. The dominant material removal mechanism of step liberation from etch pit walls followed by retreat across terrace areas is consistent with previous work on inorganic crystals under far-from-equilibrium conditions. ${ }^{44,45,88}$ However, unlike previous work, our experiments show that the propagation rate of these steps has a strong dependence on surface topography. In addition, the fluid ionic strength plays a role in the dissolution rate. The measured step retreat rates indicate that dissolution is faster in the higher ionic strength solutions, i.e. the $0.4 \mathrm{M} \mathrm{NaCl}$ and 0.1 $\mathrm{M} \mathrm{MgSO}_{4}$, than in deionized water. Given that the equilibrium solubility of fluoranthene is low with relatively fast detachment kinetics, it is likely that the overall rate of step retreat is controlled by the rate at which dissolved species diffuse away from the reaction sites. Accumulation of molecules between closely spaced steps at steep topographic features (islands and etch pits) results in a deceleration of step retreat rates compared to isolated steps. Based on our observations, we suggest that the presence of ions disrupts the water structure, enhancing release and/or transport of fluoranthene at the crystal surface. However, the exact mechanisms governing elevated fluoranthene dissolution rates in higher ionic strength solutions should be explored further.

For future studies, we recommend that the effect of fluoranthene adsorption or release from mixed organic materials should also be tested with respect to solution composition, as bonding between macromolecules may vary and the presence of charged and polar organic molecules will change solid surface hydration. Similarly, studies investigating the solution compositions expected in soils and changes in this composition induced through acid rain events or the inclusion of common surfactants, such as sodium lauryl sulfate, ${ }^{89}$ would also provide important information for $\mathrm{PAH}$ mobility in nature. Furthermore, our results indicate that at temperatures close to the ambient Earth surface, the solution's ionic strength will play an important role in mediating the release of fluoranthene into aqueous solutions. However, our results indicate that for higher temperature aqueous alteration on meteorites and asteroids, the effect of solution composition on fluoranthene solubility will be minimal. This can be linked to thermodynamic consequences of changing the water structure and potential kinetic enhancement of specific processes required for molecule release from and propagation along a hydrated surface. This hypothesis should be verified using more advanced methodology that can directly uncover the hydration structure at the surface on orientated crystal samples. If this effect is observed at the macroscale, the link between fluoranthene release and solution composition will be important for modeling contaminated aqueous environments on Earth as well as enhancing fluoranthene breakdown strategies.

\section{ASSOCIATED CONTENT}

\section{S Supporting Information}

The Supporting Information is available free of charge on the ACS Publications website at DOI: 10.1021/acsearthspacechem. 8 b00120.

Statistical treatment of resulting data in the frequency domain (PDF)

Supplementary video showing a sequence of step movement around islands (Figure 2a, Figure 3) on the surface of a fluoranthene crystal, which constitutes the most complex topography (AVI)

\section{AUTHOR INFORMATION}

\section{Corresponding Author}

*E-mail: H.E.King@uu.nl.

ORCID

Helen E. King: 0000-0002-1825-782X

Funding

This project was funded by Spinoza prize awarded to A.G.G.M Tielens.

Notes

The authors declare no competing financial interest.

\section{ACKNOWLEDGMENTS}

The authors would like to thank Dr. Suzanne Atkins for her assistance with data analysis. All analytical work was conducted at Department of Earth Sciences, Faculty of Geosciences, Utrecht University.

\section{REFERENCES}

(1) Manoli, E.; Samara, C. Polycyclic aromatic hydrocarbons in natural waters: sources, occurrence and analysis. TrAC, Trends Anal. Chem. 1999, 18 (6), 417-428.

(2) Abdel-Shafy, H. I.; Mansour, M. S. M. A review on polycyclic aromatic hydrocarbons: source, environmental impact, effect on human health and remediation. Egypt. J. Pet. 2016, 25 (1), 107-123.

(3) Liu, G.; Niu, Z.; Van Niekerk, D.; Xue, J.; Zheng, L. Polycyclic aromatic hydrocarbons (PAHs) from coal combustion: emissions, analysis, and toxicology. In Reviews of Environmental Contamination and Toxicology; Whitacre, D. M., Ed.; Springer New York: New York, 2008.

(4) Mastral, A. M.; Callén, M. S. A review on polycyclic aromatic hydrocarbon (PAH) emissions from energy generation. Environ. Sci. Technol. 2000, 34 (15), 3051-3057.

(5) Stracquadanio, M.; Dinelli, E.; Trombini, C. Role of volcanic dust in the atmospheric transport and deposition of polycyclic aromatic hydrocarbons and mercury. J. Environ. Monit. 2003, 5 (6), 984-988.

(6) Reynaud, S.; Deschaux, P. The effects of polycyclic aromatic hydrocarbons on the immune system of fish: A review. Aquat. Toxicol. 2006, 77 (2), 229-238. 
(7) Dunier, M.; Siwicki, A. K. Effects of pesticides and other organic pollutants in the aquatic environment on immunity of fish: a review. Fish Shellfish Immunol. 1993, 3 (6), 423-438.

(8) IARC Working Group. Some non-heterocyclic polycyclic aromatic hydrocarbons and some related exposures. In IARC Monographs on the Evaluation of Carcinogenic Risks to Humans; 2010; Vol. 92.

(9) Andersson, J. T.; Achten, C. Time to say goodbye to the 16 EPA PAHs? Toward an up-to-date use of PACs for environmental purposes. Polycyclic Aromat. Compd. 2015, 35 (2-4), 330-354.

(10) Keith, L. H. The source of U.S. EPA's sixteen PAH priority pollutants. Polycyclic Aromat. Compd. 2015, 35 (2-4), 147-160.

(11) Lamichhane, S.; Bal Krishna, K. C.; Sarukkalige, R. Polycyclic aromatic hydrocarbons (PAHs) removal by sorption: A review. Chemosphere 2016, 148, 336-353.

(12) Rubio-Clemente, A.; Torres-Palma, R. A.; Peñuela, G. A. Removal of polycyclic aromatic hydrocarbons in aqueous environment by chemical treatments: A review. Sci. Total Environ. 2014, 478, 201-225.

(13) Haritash, A. K.; Kaushik, C. P. Biodegradation aspects of polycyclic aromatic hydrocarbons (PAHs): a review. J. Hazard. Mater. 2009, 169 (1), 1-15.

(14) Pering, K. L.; Ponnamperuma, C. Aromatic Hydrocarbons in the Murchison Meteorite. Science 1971, 173 (3993), 237-239.

(15) Basile, B. P.; Middleditch, B. S.; Oró, J. Polycyclic aromatic hydrocarbons in the Murchison meteorite. Org. Geochem. 1984, 5 (4), 211-216.

(16) Becker, L.; Bunch, T. E. Fullerenes, fulleranes and polycyclic aromatic hydrocarbons in the Allende meteorite. Meteorit. Planet. Sci. 1997, 32 (4), 479-487.

(17) De Vries, M. S.; Reihs, K.; Wendt, H. R.; Golden, W. G.; Hunziker, H. E.; Fleming, R.; Peterson, E.; Chang, S. A search for C60 in carbonaceous chondrites. Geochim. Cosmochim. Acta 1993, 57 (4), 933-938.

(18) Hahn, J. H.; Zenobi, R.; Bada, J. L.; Zare, R. N. Application of two-step laser mass spectrometry to cosmogeochemistry: direct analysis of meteorites. Science 1988, 239 (4847), 1523-1525.

(19) Plows, F. L.; Elsila, J. E.; Zare, R. N.; Buseck, P. R. Evidence that polycyclic aromatic hydrocarbons in two carbonaceous chondrites predate parent-body formation. Geochim. Cosmochim. Acta 2003, 67 (7), 1429-1436.

(20) Shock, E. L.; Schulte, M. D. Amino-acid synthesis in carbonaceous meteorites by aqueous alteration of polycyclic aromatic hydrocarbons. Nature 1990, 343 (6260), 728-731.

(21) May, W. E.; Wasik, S. P.; Freeman, D. H. Determination of the solubility behavior of some polycyclic aromatic hydrocarbons in water. Anal. Chem. 1978, 50 (7), 997-1000.

(22) Hamaker, J. W.; Thompson, J. M. Adsorption. In Chemicals in the Soil Environment; Goring, C. M., Hamaker, J. M., Eds.; M. Dekker: New York, 1972; Vol. 1.

(23) Voice, T. C.; Weber, W. J. Sorption of hydrophobic compounds by sediments, soils and suspended solids-I. Theory and background. Water Res. 1983, 17 (10), 1433-1441.

(24) Wilcke, W. SYNOPSIS Polycyclic Aromatic Hydrocarbons (PAHs) in Soil - a Review. J. Plant Nutr. Soil Sci. 2000, 163 (3), 229-248.

(25) Pearlman, R. S.; Yalkowsky, S. H.; Banerjee, S. Water solubilities of polynuclear aromatic and heteroaromatic compounds. J. Phys. Chem. Ref. Data 1984, 13 (2), 555-562.

(26) Mackay, D.; Shiu, W. Y. Aqueous solubility of polynuclear aromatic hydrocarbons. J. Chem. Eng. Data 1977, 22 (4), 399-402.

(27) Whitehouse, B. G. The effects of temperature and salinity on the aqueous solubility of polynuclear aromatic hydrocarbons. Mar. Chem. 1984, 14 (4), 319-332.

(28) Karásek, P.; Planeta, J.; Roth, M. Solubility of solid polycyclic aromatic hydrocarbons in pressurized hot water: correlation with pure component properties. Ind. Eng. Chem. Res. 2006, 45 (12), $4454-4460$
(29) Miller, D. J.; Hawthorne, S. B.; Gizir, A. M.; Clifford, A. A. Solubility of polycyclic aromatic hydrocarbons in subcritical water from 298 to 498 K. J. Chem. Eng. Data 1998, 43 (6), 1043-1047.

(30) King, H. E.; Putnis, C. V. Direct observations of the influence of solution composition on magnesite dissolution. Geochim. Cosmochim. Acta 2013, 109, 113-126.

(31) Gross, L.; Mohn, F.; Moll, N.; Schuler, B.; Criado, A.; Guitián, E.; Peña, D.; Gourdon, A.; Meyer, G. Bond-order discrimination by atomic force microscopy. Science 2012, 337 (6100), 1326-1329.

(32) Malkin, A. J.; Land, T. A.; Kuznetsov, Y. G.; McPherson, A.; DeYoreo, J. J. Investigation of Virus Crystal Growth Mechanisms by In Situ Atomic Force Microscopy. Phys. Rev. Lett. 1995, 75 (14), 2778-2781.

(33) Danesh, A.; Connell, S. D.; Davies, M. C.; Roberts, C. J.; Tendler, S. J. B.; Williams, P. M.; Wilkins, M. J. An In Situ Dissolution Study of Aspirin Crystal Planes (100) and (001) by Atomic Force Microscopy. Pharm. Res. 2001, 18 (3), 299-303.

(34) Lal, R.; John, S. A. Biological applications of atomic force microscopy. American Journal of Physiology-Cell Physiology 1994, 266 (1), $\mathrm{C} 1-\mathrm{C} 21$.

(35) Pashkova, G. V.; Revenko, A. G. A Review of Application of Total Reflection X-ray Fluorescence Spectrometry to Water Analysis. Appl. Spectrosc. Rev. 2015, 50 (6), 443-472.

(36) Millero, F. J. The physical chemistry of seawater. Annu. Rev. Earth Planet. Sci. 1974, 2 (1), 101-150.

(37) Ryzhenko, B. N.; Cherkasova, E. V. Chemical composition of natural waters and brines as a result of hydrogeochemical processes in water-rock-gas systems. Geochem. Int. 2012, 50 (13), 1101-1150.

(38) Airieau, S. A.; Farquhar, J.; Thiemens, M. H.; Leshin, L. A.; Bao, H.; Young, E. Planetesimal sulfate and aqueous alteration in CM and CI carbonaceous chondrites. Geochim. Cosmochim. Acta 2005, 69 (16), 4167-4172.

(39) Cacace, M. G.; Landau, E. M.; Ramsden, J. J. The Hofmeister series: salt and solvent effects on interfacial phenomena. Q. Rev. Biophys. 1997, 30 (3), 241-277.

(40) Hribar, B.; Southall, N. T.; Vlachy, V.; Dill, K. A. How ions affect the structure of water. J. Am. Chem. Soc. 2002, 124 (41), $12302-12311$.

(41) Zhang, Y.; Cremer, P. S. Interactions between macromolecules and ions: the Hofmeister series. Curr. Opin. Chem. Biol. 2006, 10 (6), $658-663$

(42) Marciniak, B. The growth, morphology and perfection of fluoranthene crystals grown from supercooled chlorine derivative solutions on spontaneously formed seeds. J. Cryst. Growth 2002, 236 (1), 333-346.

(43) Eckel, D. F.; Balogh, M. P.; Fasulo, P. D.; Rodgers, W. R. Assessing organo-clay dispersion in polymer nanocomposites. J. Appl. Polym. Sci. 2004, 93 (3), 1110-1117.

(44) Brand, A. S.; Feng, P.; Bullard, J. W. Calcite dissolution rate spectra measured by in situ digital holographic microscopy. Geochim. Cosmochim. Acta 2017, 213, 317-329.

(45) Emmanuel, S. Mechanisms influencing micron and nanometerscale reaction rate patterns during dolostone dissolution. Chem. Geol. 2014, 363, 262-269.

(46) Jones, E.; Oliphant, E.; Peterson, P.; et al. SciPy: Open Source Scientific Tools for Python. 2001. http://www.scipy.org/. Date of access: $25-10-2018$.

(47) Wen, H.; Li, T.; Morris, K. R.; Park, K. Dissolution study on aspirin and $\alpha$-glycine crystals. J. Phys. Chem. B 2004, 108 (30), $11219-11227$.

(48) Danesh, A.; Connell, S. D.; Davies, M. C.; Roberts, C. J.; Tendler, S. J.; Williams, P. M.; Wilkins, M. An in situ dissolution study of aspirin crystal planes (100) and (001) by atomic force microscopy. Pharm. Res. 2001, 18 (3), 299-303.

(49) Jordan, G.; Higgins, S. R.; Eggleston, C. M.; Knauss, K. G.; Schmahl, W. W. Dissolution kinetics of magnesite in acidic aqueous solution, a hydrothermal atomic force microscopy (HAFM) study: step orientation and kink dynamics. Geochim. Cosmochim. Acta 2001, 65 (23), 4257-4266. 
(50) Liang, Y.; Baer, D. Anisotropic dissolution at the $\mathrm{CaCO} 3$ (1014) -water interface. Surf. Sci. 1997, 373 (2-3), 275-287.

(51) Jordan, G.; Rammensee, W. Dissolution rates of calcite (1014) obtained by scanning force microscopy: Microtopography-based dissolution kinetics on surfaces with anisotropic step velocities. Geochim. Cosmochim. Acta 1998, 62 (6), 941-947.

(52) Schwoebel, R. L.; Shipsey, E. J. Step motion on crystal surfaces. J. Appl. Phys. 1966, 37 (10), 3682-3686.

(53) Liu, F.; Metiu, H. Stability and kinetics of step motion on crystal surfaces. Phys. Rev. E: Stat. Phys., Plasmas, Fluids, Relat. Interdiscip. Top. 1994, 49 (4), 2601-2616.

(54) Krug, J.; Tonchev, V.; Stoyanov, S.; Pimpinelli, A. Scaling properties of step bunches induced by sublimation and related mechanisms. Phys. Rev. B: Condens. Matter Mater. Phys. 2005, 71 (4), 045412 .

(55) Liu, F.; Tersoff, J.; Lagally, M. Self-organization of steps in growth of strained films on vicinal substrates. Phys. Rev. Lett. 1998, 80 (6), 1268-1271.

(56) Venezuela, P.; Tersoff, J.; Floro, J.; Chason, E.; Follstaedt, D.; Liu, F.; Lagally, M. Self-organized growth of alloy superlattices. Nature 1999, 397 (6721), 678-689.

(57) Ravishankar, N.; Carter, C. B. Bunching of surface steps and facet formation on analumina surface. J. Mater. Res. 2002, 17 (1), 98106.

(58) King, H. E.; Satoh, H.; Tsukamoto, K.; Putnis, A. Nanoscale observations of magnesite growth in chloride-and sulfate-rich solutions. Environ. Sci. Technol. 2013, 47 (15), 8684-8691.

(59) Mundschau, M.; Bauer, E.; Telieps, W.; Swieḩ, W. Atomic steps on $\mathrm{Si}\{100\}$ and step dynamics during sublimation studied by lowenergy electron microscopy. Surf. Sci. 1989, 223 (3), 413-423.

(60) Cremeens, D. L.; Darmody, R. G.; Norton, L. D. Etch-pit size and shape distribution on orthoclase and pyriboles in a loess catena. Geochim. Cosmochim. Acta 1992, 56 (9), 3423-3434.

(61) Breslow, R. Hydrophobic effects on simple organic reactions in water. Acc. Chem. Res. 1991, 24 (6), 159-164.

(62) Jonker, M. T.; Muijs, B. Using solid phase micro extraction to determine salting-out (Setschenow) constants for hydrophobic organic chemicals. Chemosphere 2010, 80 (3), 223-227.

(63) Marcus, Y. Effect of ions on the structure of water: structure making and breaking. Chem. Rev. 2009, 109 (3), 1346-1370.

(64) Endo, S.; Pfennigsdorff, A.; Goss, K.-U. Salting-out effect in aqueous $\mathrm{NaCl}$ solutions: trends with size and polarity of solute molecules. Environ. Sci. Technol. 2012, 46 (3), 1496-1503.

(65) Tielrooij, K.; Garcia-Araez, N.; Bonn, M.; Bakker, H. Cooperativity in ion hydration. Science 2010, 328 (5981), 10061009.

(66) Waluyo, I.; Huang, C.; Nordlund, D.; Bergmann, U.; Weiss, T. M.; Pettersson, L. G.; Nilsson, A. The structure of water in the hydration shell of cations from x-ray Raman and small angle x-ray scattering measurements. J. Chem. Phys. 2011, 134 (6), 064513.

(67) Ahmed, M.; Namboodiri, V.; Singh, A. K.; Mondal, J. A. On the intermolecular vibrational coupling, hydrogen bonding, and librational freedom of water in the hydration shell of mono-and bivalent anions. J. Chem. Phys. 2014, 141 (16), 164708.

(68) Dove, P. M.; Han, N.; De Yoreo, J. J. Mechanisms of classical crystal growth theory explain quartz and silicate dissolution behavior. Proc. Natl. Acad. Sci. U. S. A. 2005, 102 (43), 15357-15362.

(69) Ruiz-Agudo, E.; Kowacz, M.; Putnis, C.; Putnis, A. The role of background electrolytes on the kinetics and mechanism of calcite dissolution. Geochim. Cosmochim. Acta 2010, 74 (4), 1256-1267.

(70) Marutschke, C.; Walters, D.; Cleveland, J.; Hermes, I.; Bechstein, R.; Kühnle, A. Three-dimensional hydration layer mapping on the (10.4) surface of calcite using amplitude modulation atomic force microscopy. Nanotechnology 2014, 25 (33), 335703.

(71) Jäger, C.; Huisken, F.; Mutschke, H.; Jansa, I. L.; Henning, T. Formation of polycyclic aromatic hydrocarbons and carbonaceous solids in gas-phase condensation experiments. Astrophys. J. 2009, 696 (1), 706-712.
(72) Zenobi, R.; Philippoz, J.-M.; Buseck, P. R.; Zare, R. N. Spatially resolved organic analysis of the Allende meteorite. Science 1989, 246 (4933), 1026-1029.

(73) Rapacioli, M.; Calvo, F.; Spiegelman, F.; Joblin, C.; Wales, D. J. Stacked Clusters of Polycyclic Aromatic Hydrocarbon Molecules. J. Phys. Chem. A 2005, 109 (11), 2487-2497.

(74) Coughlin, R. W.; Ezra, F. S. Role of surface acidity in the adsorption of organic pollutants on the surface of carbon. Environ. Sci. Technol. 1968, 2 (4), 291-297.

(75) Yuan, M.; Tong, S.; Zhao, S.; Jia, C. Q. Adsorption of polycyclic aromatic hydrocarbons from water using petroleum coke-derived porous carbon. J. Hazard. Mater. 2010, 181 (1), 1115-1120.

(76) Saparpakorn, P.; Kim, J.; Hannongbua, S. Investigation on the binding of polycyclic aromatic hydrocarbons with soil organic matter: a theoretical approach. Molecules 2007, 12 (4), 703-715.

(77) Berlman, I. Evidence of intramolecular hydrogen bonding from spectroscopic data. Chem. Phys. Lett. 1969, 3 (2), 61-63.

(78) Schwoerer, M.; Wolf, H. C. Organic Molecular Solids; John Wiley \& Sons, 2007.

(79) Tremblay, L.; Kohl, S. D.; Rice, J. A.; Gagné, J.-P. Effects of temperature, salinity, and dissolved humic substances on the sorption of polycyclic aromatic hydrocarbons to estuarine particles. Mar. Chem. 2005, 96 (1-2), 21-34.

(80) Icenhower, J. P.; Dove, P. M. The dissolution kinetics of amorphous silica into sodium chloride solutions: effects of temperature and ionic strength. Geochim. Cosmochim. Acta 2000, 64 (24), 4193-4203.

(81) Hilscherova, K.; Dusek, L.; Kubik, V.; Cupr, P.; Hofman, J.; Klanova, J.; Holoubek, I. Redistribution of organic pollutants in river sediments and alluvial soils related to major floods. J. Soils Sediments 2007, 7 (3), 167-177.

(82) Flotron, V.; Delteil, C.; Padellec, Y.; Camel, V. Removal of sorbed polycyclic aromatic hydrocarbons from soil, sludge and sediment samples using the Fenton's reagent process. Chemosphere 2005, 59 (10), 1427-1437.

(83) Brearley, A. J. The action of water. In Meteorites and the Early Solar System II; Lauretta, D. S., McSween, H. Y. J., Eds.; University of Arizona Press: Tucson, 2006.

(84) Oparin, R.; Fedotova, M.; Trostin, V. Relationship between the structural state of water and the character of ion hydration in concentrated 1:1 aqueous solutions of electrolytes in extreme conditions. J. Struct. Chem. 2002, 43 (3), 467-472.

(85) Yalkowsky, S. H.; He, Y.; Jain, P. Solubility Data. In Handbook of Aqueous Solubility Data, 2nd ed.; CRC Press, 2010.

(86) Pye, C. C.; Rudolph, W. An ab initio and Raman investigation of magnesium (II) hydration. J. Phys. Chem. A 1998, 102 (48), 99339943.

(87) Ikai, A. STM and AFM of bio/organic molecules and structures. Surf. Sci. Rep. 1996, 26 (8), 261-332.

(88) Fischer, C.; Kurganskaya, I.; Schäfer, T.; Lüttge, A. Variability of crystal surface reactivity: What do we know? Appl. Geochem. 2014, 43, $132-157$.

(89) Bondi, C. A. M.; Marks, J. L.; Wroblewski, L. B.; Raatikainen, H. S.; Lenox, S. R.; Gebhardt, K. E. Human and Environmental Toxicity of Sodium Lauryl Sulfate (SLS): Evidence for Safe Use in Household Cleaning Products. Environ. Health Insights 2015, 9, 2732. 